\title{
The Echocardiographic Tei-index Compared to Transpulmonary Thermodilution Measurement With Different Hemodynamic Biomodels
}

\section{Kobr $\mathrm{J}^{*}$ and Pizingerova $\mathrm{K}$}

Department of Pediatrics, Charles University in Prague, Faculty of Medicine in Pilsen, Czech Republic

${ }^{*}$ Corresponding author: Kobr J, Department of Pediatrics, Charles University in Prague, Faculty of Medicine in Pilsen, Alej Svobody 80, 30460 Pilsen, Czech Republic, E-mail: jikobr93@gmail.com

Citation: Kobr J, Pizingerova K (2014) The Echocardiographic Tei-index Compared to Transpulmonary Thermodilution Measurement With Different Hemodynamic Biomodels. J Clin Exp Res Cardiol 1(1): 103. doi: $10.15744 / 2394-6504.1 .103$

Received Date: July 07, 2014 Accepted Date: July 14, 2014 Published Date: July 21, 2014

\begin{abstract}
Objective: To compare Doppler flow Tei-indexes with standard intermittent transpulmonary thermodilution measurement with different hemodynamic loading conditions.

Type of study: Experimental comparative study.

Materials and methods: Total 48 piglets ( 6 weeks old, average weight $23 \mathrm{~kg}$ ) under general anesthesia, were divided into groups under cardiac loading conditions (at rest, with increased left ventricular afterload, with increased right ventricular preload). At 60 and 120 minutes the animals were examined by echocardiography and simultaneously transpulmonary thermodilution was used to measure cardiac output. Tei-indexes data were compared with invasively monitored haemodynamic data.

Results: A total of 1632 parallel data were obtained. Correlation was found between values of right Tei-index and changes in right ventricular preload $(p<0.05)$ and afterload $(p<0.01)$. Correlation was also found between left Tei-index values and changes of left ventricular preload $(p<0.001)$, afterload $(p<0.001)$, stroke volume $(p<0.01)$, and cardiac output $(p<0.01)$.

Conclusions: Tei-index as global myocardial performance selectively for the right and left ventricle can be recommended for monitoring of circulation and cardiac performance.
\end{abstract}

Keywords: Tei-index; Transpulmonary thermodilution; Hemodynamics; Piglets

\section{Introduction}

Cardiopulmonary interaction plays an essential role in critically ill pediatric patients. Accurate assessment of cardiac output and myocardial function has been considered vital in the successful treatment of any such patients. There are several techniques for monitoring cardiac output in seriously ill patients. The use of transpulmonary thermodilution technique for cardiac output measurements via in-dwelling pulmonary arterial catheter is considered one of the most reliable methods of hemodynamic monitoring in paediatric patients. However, its invasive nature is not without inherent risks [1-2].

Non-invasive methods of cardiovascular functional monitoring are therefore particularly appealing in children. The myocardial performance indexes (MPIs) as Tei-indexes has been demonstrated to fulfill criteria as a non-invasive, easily obtainable, and reproducible tool for global myocardial performance assessment in both adult and pediatric patients [3-5]. The technique is based on Doppler flow derived time intervals within the cardiac cycle and used to assess global, systolic and diastolic myocardial function. It also allows for separate assessment of the left and right ventricular performance and its increasing value represents myocardial dysfunction [6]. Given the persistent controversy about load dependence of MPIs [7-9], we compared hemodynamic parameters achieved using invasive monitoring with values of Tei-indexes in an experimental setting.

\section{Materials and Methods}

The study was conducted with the approval of a multidisciplinary institutional ethics committee in an EU accredited experimental centre of the Faculty of Medicine of Charles University in Pilsen, Czech Republic. Respecting the principles of Helsinki Declaration this study was part of an ongoing experimental studies. 
Forty-eight clinically healthy piglets (aged 6 weeks, mean weight $23 \mathrm{~kg}$ with range between 18-27kg, male to female ratio $1: 2$ anesthetised, endotracheally intubated, introduced by pulmonary artery catheter and divided into groups. Control Group A (n $=48$ ) included spontaneously breathing animals without changes in hemodynamics. After completing the measurements in this group, the animals were generally anesthetised, mechanically ventilated with neuromuscular block, and divided into two groups according to further surgical interventions: Group B $(\mathrm{n}=24)$ formed the hemodynamic model of animals with cross clamping of the abdominal aorta above the origin of renal arteries before kidney transplantation $[10,11]$ or experimentally created abdominal aortic aneurysm [12-14], and Group C $(n=24)$ comprised of animals with partial occlusion of the portal bed via right portal vein embolization as biomodel of liver regeneration [15-18]. In the normal course of events the high volume of venous blood from the digestive tract of unpaired organs arises through the portal circulation to the liver on the basis of a pressure gradient. Acute occlusion of half of the entire portal venous bed causes early portal hypertension and transient changes in regional hemodynamics. Immediate adaptation after surgery leads to a reduction in liver flow lasting several hours, and conversely increases flow through the natural porto-systemic venous connections into the lower vena cava [19,20]. Temporary increase in-flow in the lower vena cava was used to create an experimental hemodynamic biomodel of increased right ventricle preload and diastolic filling [21,22].

The internal jugular vein was cannulated for central venous access using the Seldinger percutaneous technique and a Swan-Ganz thermodilution pulmonary catheter was introduced. The femoral artery was used for direct arterial blood pressure monitoring via the arterial catheter. The animals were examined by echocardiography to acquire data for Tei-indexes calculations, invasively monitored hemodynamic data were recorded, and transpulmonary thermodilution technique was used to parallel measure cardiac output via pulmonary artery catheter.

\section{General anesthesia and ventilator support}

Premedication was given by intramuscular administration of atropine $0.07 \mathrm{mg} / \mathrm{kg}$ and azaperone $5.0 \mathrm{mg} / \mathrm{kg}$. General anaesthesia was induced by intravenous administration of thiopental $10 \mathrm{mg} / \mathrm{kg}$ and all animals were orotracheally intubated. Combined general anesthesia was maintained by intravenous ketamine $1.5-3.0 \mathrm{mg} / \mathrm{kg}$ or fentanyl $0.5-1.0 \mathrm{microg} / \mathrm{kg}$ with azaperone $3.0-4.0 \mathrm{mg} / \mathrm{kg}$ and peripheral muscle paralysis by pancuronium $0.1-0.2 \mathrm{mg} / \mathrm{kg}[23]$.

Animals in Group A were breathing spontaneously with continuous positive airway pressure support at $2 \mathrm{cmH}_{2} \mathrm{O}$ and $\mathrm{FiO}_{2} 0.21$. Animals in Groups B, and D were mechanically ventilated using a servo-ventilator (Siemens Elema900C, Germany) in pressure controlled mode with the following settings: $\mathrm{P}_{\text {insp }} 15 \mathrm{cmH}_{2}$, rate 24 breath/min, PEEP $6 \mathrm{cmH}_{2} \mathrm{O}, \mathrm{I}: \mathrm{E}$ 0.7, FiO 20.21 .

\section{Study Protocol}

Experimental work in all piglets utilised tracheal intubation and establishing invasive entry under general anaesthesia. Following a sixty minute recovery period the first measurement reading was taken and echocardiographic imaging performed (time-1). After a further sixty minutes, all measurements were repeated (time-2).

\section{Echocardiographic assessment and Tei indexes calculations}

A transthoracic echocardiogram was performed using 3.5-5.0 MHz probe (Sonoline Siem, Siemens; Germany). A two-dimensional echocardiogram and pulse wave Doppler were used in apical four-chamber view to acquire data from blood flow through atrioventricular and in left parasternal view of the semilunar valves, respectively. Care was taken to align the transducer beam as closely as possible to the blood flow axis. Doppler signals for the left and right ventricular valves were not acquired simultaneously. No angle correction was made. Doppler and ECG tracings were recorded and stored digitally.

The blood flow time intervals were measured by taking the three most distinct Doppler trace in a frozen template. The time interval from the cessation to the onset of mitral or tricuspid inflow (AVCO) was measured. This interval is equal to the sum of isovolumic contraction time, ejection time, and isovolumic relaxation time. Left and right ventricular ejection time (ET) was measured in the ascending aorta or main pulmonary artery just above the corresponding valve. Myocardial performance index was then calculated using formula (AVCO - ET) / ET selectively for the right $\left(_{\mathrm{RV}} \mathrm{MPI}\right)$ and left $\left.{ }_{\mathrm{LV}} \mathrm{MPI}\right)$ heart ventricle $[7,24,25]$. Thus the calculated value was divided by the current value of the R-R interval of simultaneously recorded electrocardiogram to exclude the impact of variations in heart rate on the measurement result. This method was used to calculate the myocardial performance index for each of the three measurements. The average value of these three indices was stored in a database. This data was used for statistical processing.

\section{Measurement of cardiac output and hemodynamic data acquisition}

Cardiac output was measured by intermittent transpulmonary thermodilution. Under ultrasound guidance a Swan-Ganz thermodilution catheter was positioned in the pulmonary artery. The average temperature of $38.5^{\circ} \mathrm{C}$ measured in the pulmonary artery allowed for adequate thermal difference with the test solution ( $0.9 \mathrm{M}$ solution of sodium chloride at $\left.21{ }^{\circ} \mathrm{C}\right)$. Standard technique was used to assess cardiac output by flash application of $10 \mathrm{ml}$ test solution into proximal port of pulmonary artery catheter and subsequent temperature monitoring at the catheter tip [1]. Moreover, no fluid replacement bolus or any other therapeutic intervention was performed at the time of all data acquisition. We feel that any potential inaccuracies of this method are counterbalanced when the same investigator performs all the measurements in each subject. 
Cardiac output (CO, ml/min) was measured intermittently and its value was displayed directly on the monitor (Nihon-Kohden, Japan) and expressed as mean value from the five consecutive measurements in 30 second intervals. The following haemodynamic data were acquired, calculated and recorded: heart rate (HR, beat/min), mean central venous pressure (CVP, $\mathrm{mmHg}), \mathrm{mean}$ right heart ventricle pressure (RVP, $\mathrm{mmHg}$ ), mean pulmonary arterial pressure (PAP, mmHg), mean pulmonary arterial occlusive, capillary wedge pressure (PAoP, $\mathrm{mmHg}$ ), mean arterial pressure (MAP, mmHg), stroke volume (SV, ml), cardiac index (CI, l/min/ $\mathrm{m}^{2}$ ) as CO/BSA, systemic vascular resistance (SVR, dyn.sec/ $\mathrm{cm}^{5}$ ) according to the formula MAP-CVP/CO, pulmonary arteriolarvascular resistance (PVR, dyn.sec/ $\left.\mathrm{cm}^{5}\right)$ by the formula PAP-PAoP/CO. Body surface area $\left(\mathrm{BSA}, \mathrm{m}^{2}\right)$ of animals was calculated using the following Meehe's formula: $0.087 \mathrm{x}$ weight / 0.66 [7]. All these parameters were also expressed as mean values from the five consecutive measurements in 30 second intervals.

\section{Statistical analysis}

Parametric data were expressed as median, standard deviation (SD) and 95\% confidence interval (95\% CI). Pearson's analysis and polynominal regression was used to compare the data obtained. Collinearity between variables was tested prior to modelling by computing the correlation of estimates, with a $\mathrm{R}^{2}>0.5$ considered to be significant. For qualitative analysis of accuracy of the variables reference interval dispersion, the linearity, reproducibility agreement were used [26]. $P$ values $<0.05$ were considered statistically significant. All data were analyzed using statistical software (Analyze-it211 Software Ltd.).

\section{Results}

A total of 1632 parallels data sets including data on Tei-indexes, hemodynamics and cardiac output measurements were acquired. Echocardiographic measurements of Tei-indices (MPIs; $n=192$ ) showed excellent reproducibility $(p<0.01)$ and acceptable diversity $(\mathrm{p}=0.082)$. The files of all data and differences in quality between the groups were not statistically significant.

Differences between the values of data obtained in the time-1, time- 2 of study in groups were not statistically significant. A summary of all data values obtained in the groups and the differences between Groups B, C and control Group A are listed in Table 1 .

\begin{tabular}{|c|c|c|c|c|c|}
\hline Variables & A & B & $\begin{array}{c}\mathbf{P}< \\
\mathbf{B}_{\mathrm{vs}} \cdot \mathbf{A}\end{array}$ & C & $\begin{array}{c}\mathbf{P}< \\
\mathrm{C}_{\mathrm{vs}} . \mathrm{A}\end{array}$ \\
\hline HR & $88 \pm 9.03(8.7)$ & $94 \pm 7.30(6.0)$ & NS & $98 \pm 6.25(5.73)$ & NS \\
\hline CVP & $2.0 \pm 1.46(1.6)$ & $2.3 \pm 1.15(1.0)$ & NS & $2.5 \pm 0.97(1.7)$ & NS \\
\hline SBP & $99.5 \pm 15.46(17.7)$ & $98.2 \pm 13.05(12.2)$ & NS & $97.7 \pm 14.83(13.2)$ & NS \\
\hline MAP & $77 \pm 10.46(9.2)$ & $78 \pm 15.12(13.3)$ & NS & $75 \pm 5.12(4.5)$ & NS \\
\hline DBP & $66 \pm 10.46(9.582)$ & $73 \pm 12.33(11.8)$ & 0.05 & $78 \pm 10.33(12.6)$ & 0.05 \\
\hline MAP-CVP & $73.71 \pm 2.13(1.8)$ & $74.22 \pm 1.78(1.2)$ & NS & $69.13 \pm 3.8(3.1)$ & 0.05 \\
\hline RVP & $9.04 \pm 1.87(1.0)$ & $9.45 \pm 1.74(3.1)$ & NS & $14.43 \pm 3.04(2.0)$ & 0.05 \\
\hline PAP & $16.02 \pm 3.13(3.9)$ & $16.50 \pm 2.53(2.9)$ & NS & $17.21 \pm 5.30(3.8)$ & 0.05 \\
\hline PAoP & $6.91 \pm 5.87(3.0)$ & $10.64 \pm 2.33(2.6)$ & 0.01 & $13.53 \pm 2.44(1.681)$ & 0.01 \\
\hline SV & $18.03 \pm 2.50(2.9)$ & $17.93 \pm 2.84(4.2)$ & NS & $15.21 \pm 2.62(4.0)$ & 0.01 \\
\hline PVR & $404 \pm 52.23(41.9)$ & $409 \pm 58.32(55.3)$ & NS & $440 \pm 82.24(58.2)$ & 0.05 \\
\hline SVR & $1580 \pm 680.31(90.2)$ & $1595 \pm 480.01(99.7)$ & NS & $2435 \pm 130.20(93.2)$ & 0.01 \\
\hline $\mathrm{CO}$ & $2.91 \pm 0.98(1.3)$ & $2.66 \pm 0.83(0.9)$ & NS & $1.94 \pm 1.01(1.1)$ & 0.01 \\
\hline $\mathrm{CI}$ & $1.34 \pm 0.30(0.5)$ & $1.25 \pm 0.28(0.3)$ & NS & $0.64 \pm 0.37(0.2)$ & 0.01 \\
\hline SF & $0.43 \pm 0.12(0.09)$ & $0.64 \pm 0.07(0.06)$ & 0.05 & $0.57 \pm 0.09(0.08)$ & 0.05 \\
\hline${ }_{\mathrm{RV}} \mathrm{MPI}$ & $0.22 \pm 0.02(0.02)$ & $0.24 \pm 0.01(0.01)$ & NS & $0.25 \pm 0.02(0.02)$ & 0.05 \\
\hline LV MPI & $0.29 \pm 0.03(0.02)$ & $0.30 \pm 0.04(0.03)$ & NS & $0.28 \pm 0.02(0.02)$ & NS \\
\hline
\end{tabular}

A, spontaneous breathing $(n=48)$; B, mechanically ventilated piglets with cross clamping of the abdominal aorta $(n=24)$; , ventilated animals with right portal vein embolization $(\mathrm{n}=24)$.

HR, heart rate (beat/min); CVP, mean central venous pressure ( $\mathrm{mmHg})$; SBP, systolic blood pressure (mmHg); MAP, mean artery pressure (mmHg); DBP, diastolic blood pressure (mmHg); MAP-CVP, difference of mean systemic pressures (mmHg); RVP, mean right ventricle pressure (mmHg); PAP, mean pulmonary artery pressure $(\mathrm{mmHg})$; PAoP, mean pulmonary artery occlusive pressure $(\mathrm{mmHg}) ; \mathrm{SV}$, stroke volume $(\mathrm{ml})$; SVR, systemic vascular resistance $\left(\right.$ dyn.sec/ $\left./ \mathrm{cm}^{5}\right)$; PVR, pulmonary vascular resistance $\left(\operatorname{dyn} . \mathrm{sec} / \mathrm{cm}^{5}\right) ; \mathrm{CO}$, cardiac output $(1 / \mathrm{min}) ; \mathrm{CI}$, cardiac index $\left(1 / \mathrm{min} / \mathrm{m}^{2}\right) ;$, MPI, right ventricle myocardial

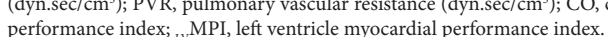

NS, not significant; $P<$, values of $P$.

All values are given as median \pm SD, $95 \%$ confidence interval $(95 \% \mathrm{CI})$.

Table 1: Data values obtained in groups and the differences between Groups B, C and control Group A 
In all ventilated (Groups B, C) ${ }_{R V} \mathrm{MPI},{ }_{\mathrm{LV}} \mathrm{MPI}, \mathrm{CVP}$ and PAoP were higher compared with spontaneously breathing animals of Group A. In Groups C the values of HR, SV, CO, CI, PVR and SVR were higher compared with Group A, while there were no differences between Group B and Group A.

Correlations of the ${ }_{\mathrm{RV}} \mathrm{MPI}$ and ${ }_{\mathrm{LV}} \mathrm{MPI}$ with the values of standard haemodynamic parameters in individual Groups B, and C are listed in Table 2.

\begin{tabular}{|c|c|c|c|c|c|}
\hline \multirow{2}{*}{$\begin{array}{c}\text { Dependent } \\
\text { Variables }\end{array}$} & $\begin{array}{c}\text { Independent } \\
\text { Variables }\end{array}$ & \multicolumn{2}{|c|}{ B } & \multicolumn{2}{|c|}{ C } \\
\cline { 3 - 6 } & & $R^{2}$ & $P^{<}$ & $R^{2}$ & $P^{<}$ \\
\hline \multirow{4}{*}{ RV MPI } & PVR & 0.78 & 0.01 & 0.87 & 0.001 \\
\cline { 2 - 6 } & CVP & 0.35 & NS & 0.83 & 0.001 \\
\cline { 2 - 6 } & MAP-CVP & 0.28 & NS & 0.82 & 0.001 \\
\cline { 2 - 6 } & RVP & 0.88 & 0.001 & 0.75 & 0.01 \\
\hline \multirow{4}{*}{ LV MPI } & SVR & 0.84 & 0.001 & 0.68 & 0.05 \\
\cline { 2 - 6 } & PAoP & 0.75 & 0.01 & 0.89 & 0.001 \\
\cline { 2 - 6 } & SV & 0.66 & 0.05 & 0.59 & 0.05 \\
\cline { 2 - 6 } & CO & 0.78 & 0.01 & 0.81 & 0.01 \\
\cline { 2 - 6 } & MAP-CVP & 0.57 & 0.05 & 0.60 & 0.05 \\
\hline
\end{tabular}

MPI, myocardial performance index of right ventricle; ${ }_{\mathrm{H}} \mathrm{MPI}$, myocardial performance index of left ventricle; HR, heart rate (beat/min); CVP, mean central venous pressure $(\mathrm{mmHg})$; RVP, mean right ventricle pressure $(\mathrm{mmHg})$; PAP, mean pulmonary artery pressure (mmHg); PAoP, mean pulmonary artery occlusive pressure (mmHg); MAP, mean artery pressure (mmHg); $\mathrm{SV}$, stroke volume $(\mathrm{ml}) ; \mathrm{CO}$, cardiac output $(\mathrm{l} / \mathrm{min}) ;$ MAP-CVP, difference of mean systemic pressures $(\mathrm{mmHg})$; SVR, systemic vascular resistance (dyn.sec/ $\left.\mathrm{cm}^{5}\right)$; PVR, pulmonary vascular resistance $\left(\right.$ dyn.sec/ $\left./ \mathrm{cm}^{5}\right)$

NS, not significant; $\mathrm{R}^{2}$, multiple Pearson's residual index; $p<$, significance values

Table 2: Correlations of myocardial performance indexes with PAC haemodynamic parameters in the groups ventilated animals $(\mathrm{n}=816)$

The set of all data obtained in the study was used for the overall correlation between ${ }_{\mathrm{RV}}{ }_{\mathrm{MPI}}$ and ${ }_{\mathrm{LV}} \mathrm{MPI}$ and haemodynamic parameters are presented in Table 3.

\begin{tabular}{|c|c|c|c|c|}
\hline Dependent Variables & Independent Variables & 95\% CI interval & $\boldsymbol{R}^{2}$ & $P<$ \\
\hline \multirow{2}{*}{${ }_{\mathrm{NV}} \mathrm{MPI}$} & $\mathrm{PVR}$ & 0.57 to 0.75 & 0.67 & 0.01 \\
\cline { 2 - 5 } & $\mathrm{CVP}$ & 0.27 to 0.53 & 0.51 & 0.05 \\
\hline \multirow{3}{*}{${ }_{\text {Lv }}$ MPI } & SVR & 0.77 to 0.87 & 0.86 & 0.001 \\
\cline { 2 - 5 } & PAoP & 0.64 to 0.79 & 0.72 & 0.001 \\
\cline { 2 - 5 } & $\mathrm{SV}$ & -0.53 to -0.19 & 0.62 & 0.01 \\
\cline { 2 - 5 } & $\mathrm{CO}$ & -0.73 to -0.54 & 0.64 & 0.01 \\
\cline { 2 - 5 } & $\mathrm{MAP}$ & -0.86 to -0.75 & 0.82 & 0.001 \\
\hline
\end{tabular}

MPI, myocardial performance index of right ventricle; ${ }_{W} \mathrm{MPI}$, myocardial performance index of left ventricle; CVP, mean central venous pressure (mmHg); RVP, mean right ventricle pressure $(\mathrm{mmHg})$; $\mathrm{PAoP}$, mean pulmonary artery occlusive pressure $(\mathrm{mmHg})$; PVR, pulmonary vascular resistance $\left(\mathrm{dyn} . \mathrm{sec} / \mathrm{cm}^{5}\right)$; $\mathrm{MAP}-\mathrm{CVP}$, difference of mean systemic pressures (mmHg); $\mathrm{CO}$, cardiac output (1/min); SVR, systemic vascular resistance (dyn.sec/cm5); MAP, mean artery pressure (mmHg) NS, not significant; $\mathrm{R}^{2}$, multiple Pearson's residual index; $p<$, significance values

Table 3: Correlations of myocardial performance indexes with PAC haemodynamic parameters in the set of all data obtained $(\mathrm{n}=1632)$

In spontaneously breathing piglets (Group A) ${ }_{L V} \mathrm{MPI}$ values correlated only with the SVR $\left(\mathrm{R}^{2}=0.69 ; p<0.01\right)$, but in ventilated animals (Groups B, C) correlated with the PAoP, SVR, CO, and MAP-CVP. ${ }_{\mathrm{RV}}$ MPI values in Groups C correlated with the CVP, RVP, MAP, CVP and PVR, but in Group B only with PVR and RVP. When processing all data obtained $(\mathrm{n}=1632)$ values ${ }_{\mathrm{RV}} \mathrm{MPI}$ correlated directly with the CVP and PVR. Values ${ }_{\mathrm{LV}}$ MPI correlated directly with the PAoP, SVR, and indirectly with SV, CO, and MAP.

After analyzing the entire data set $(n=1632)$ polynominal regression revealed significant correlations between the values of ${ }_{L V} \mathrm{MPI}$ versus CI $(p<0.001)$ and ${ }_{\text {LV }}$ MPI versus MAP $(p<0.001)$.

\section{Discussion}

Echocardiographic cardiac imaging and Tei-index has been used in non-invasive assessment of cardiac function for more than 15 years [6]. Wide experience was gained with its use both in experimental $[7,8,12,16,18,27,28]$ and adult clinical practice [9,29,30], respectively. It also appears to be a useful prognostic tool in adult patients with dilated cardiomyopathy [31,32], anthracyclin induced myocardial toxicity [33,34], chronic lung disease [35,36], amyloidosis [30], and Chagas disease [38]. This Tei-index of my- 
ocardial performance has been validated in pediatric patients with various congenital heart defects [3,37], and with pulmonary hypertension $[4,40]$. It has been found useful in the acute setting of pediatric cardiac intensive care as well [39,40]. Controversy has persisted about its load independence. In their original description of the index, found it independent of the degree of atrioventricular valve regurgitation $[8,30,32,35]$. They subsequently found the index correlated closely with parameters of systolic and diastolic myocardial function measured invasively $[1,34]$. However, further experimental testing of the index against acute changes in both preload and afterload conveyed some evidence about significant impact of these changes on the index values [28]. Results from our experimental study show a correlation between Tei-indices of global myocardial performance for the right ventricle and its invasively measured preload as central venous pressure and afterload as pulmonary vascular resistance. Left ventricular Tei-index also correlated with its preload as pulmonary arterial occlusion pressure and afterload as systemic vascular resistance. Both Tei-indices then inversely correlated with cardiac output. These results support load dependence of the index. It has to be stressed that all data in our study were obtained in an acute setting of experimental kidney transplantation or liver surgery. It is perhaps not surprising that myocardial function as assessed by Tei-index closely mirrors acute changes in ventricular loading conditions and afterload in particular. Any such results and their extrapolation into clinical human physiology have to be treated with caution as inter-species and even intra-species differences are likely [27,40]. Nevertheless the Tei-index being dependent on loading conditions follows changes in myocardial performation and it appears to have predictive value mainly in myocardial dysfunction. This probably reflects changes in isovolumic contraction time and ejection time most likely to be affected by disease states leading to myocardial systolic dysfunction and increased afterload. Treatment interventions altering myocardial systolic function and afterload with concomitant shortening of isovolumic contraction time and lengthening of ejection time will lead to improved values of the index [5,41].

At our clinical praxis we obviously prefer minimally invasive techniques. In critically ill children we asses the global performance of each ventricle. Over the last approximately ten years we have had excellent experience with echocardiography. Repeated bedside echocardiographic evaluation and calculations of Tei-indices with shortening fraction in combination with continuous monitoring of systemic pressures we checked the effectiveness of pharmacological circulatory support. Quality testing is for all methods of monitoring hemodynamics depend on the hands-on investigator experience. The basic levels of cardiologic morphological orientation, measurement and control of the sonographic apparatus may be achieved over an intensive course lasting several days. However, good technique using invasive thermodilution methods does take considerably longer. At our PICU, 75\% of physicians are trained in echocardiography, whilst only 5\% are experienced in thermodilution techniques. It was a logical step for us to scientifically confirm that the global preferred trend of minimally invasive techniques in determining cardiac performance, are comparable to the so-called gold standard in monitoring haemodynamics via a pulmonary artery catheter.

The authors of this work are aware that echocardiographic imaging does have its limitations, most of which are investigator dependent, e.g. angle of spread of the Doppler wave. Measurement of the time interval between the opening and closing of the atrioventricular valves (AVCO), however, is not investigator dependent. This measurement is imprecise during tachycardia where this interval is significantly shortened. The clinical assessment of each subject does not depend upon absolute values, but rather the trend of the measured parameters.

Additional limitations of study may include the fact that the study duration took place over 6 years. As the fundamental aim of the study was to achieve the greatest amount of data from a very large number of hemodynamically compromised animals, it was a logistical problem to achieve this in a shorter period of time. As the investigator, apparatus and experimental conditions throughout the entire length of the study remained constant, we feel that the end result is minimally influenced by bias. Echocardiographic cardiac imaging in piglets is hampered by the morphological uniqueness of their chest anatomy, not least by the narrow intercostals spaces. Echocardiography, introduction of pulmonary artery catheter and all measurements were performed by the same investigator in all test animals. In the statistical processing of large amounts of data was more accurate calculation of correlation and assessment different than the processing of data in each group.

All the above limitations do not detract from the importance of the Tei-index as a non-invasive, easily obtainable, and reproducible tool for assessment of biventricular global myocardial performance in the setting of experimental work and clinical intensive care.

\section{Acknowledgements}

Mr. RNDr. František Šefrna, PhD. has been a consultant-statistics of our work and include it with gratitude for active cooperation. The study was supported by Research Projects of Charles University in Prague, Faculty of Medicine in Pilsen No. MSM 00211608196096 and PRVOUK P36, grants the Ministry of Health of the Czech Republic IGA no. NA/7653-3, NR/7909-3, and grant of the Charles University in Prague GA no. 82/2000/C/LFP

\section{References}

1. Sakka SG, Reuter DA, Pevel A (2012) The Transpulmonary thermodilution technique. J Clin Monit Comput 26: 347-53.

2. Carmosino MJ, Friesen RH, Doran A, Ivy DD (2007) Perioperative complications in children with pulmonary hypertension undergoing noncardiac surgery or cardiac catheterization. Anesth Analg 104: 521-7.

3. Williams RV, Ritter S, Tani LY, Pagoto LT, Minich LL (2000) Quantitative assessment of ventricular function in children with single ventricle using the Doppler myocardial performance index. Am J Cardiol 86: 1106-10. 
4. Pratap U, Ofoe VV, Onuzo O, Kaplanova J, Franklin RCG, et al. (2004) Myocardial performance index in children with ventricular septal defect. Ces-slov Pediat 59: 271-3.

5. Lavine SJ, Conetta DA (2008) Comparison of the effect of pressure loading on left ventricular size, systolic and diastolic function in canines with left ventricular dysfunction with preserved and reduced ejection fraction. Cardiovasc Ultrasound 6: 57.

6. Tei C, Ling LH, Oh JK, Rodeheffer RJ, Tajik J, et al. (1995) Evaluation of a new Doppler index of myocardial performance. J Am Soc Echocardiography 8: 357. 7. LaCorte JC, Cabreriza SE, Rabkin DG, Prinz BF, Coku L, et al. (2003) Correlation of the Tei index with invasive measurements of ventricular function in a porcine model. J Am Soc Echocardiogr 16: 442-7.

8. Teshima K, Asano K, Iwanaga K, Koie H, Uechi M, et al. (2007) Evaluation of left ventricular Tei index (index of myocardial performance) in healthy dogs and dogs with mitral regurgitation. J Vet Med Sci 69: 117-23.

9. Murphy GS, Marymont JH, Szokol JW, Avram MJ, Vender JS (2007) Correlation of the myocardial performance index with conventional echocardiographic indices of systolic and diastolic function: a study in cardiac surgical patients. Echocardiography 24: 26-33.

10. Kuntscher V, Treska V, Racek J, Kobr J, Trefil L, et al. (2007) Does the administration of antioxidants as scavengers of reactive oxygen species in kidney transplantation really have sense? Bratisl Lek Listy 108: 385-7.

11. Treska V, Kobr J, Hasman D, Racek J, Trefil L, et al. (2009) Ischemia-reperfusion injury in kidney transplantation from non-heart-beating donor-do antioxidants or antiinflammatory drugs play any role? Bratisl Lek Listy 110: 133-6.

12. Molacek J, Treska V, Kobr J, Certik B, Skalicky T, et al. (2009) Optimalization of the model of abdominal aortic aneurysm - experiment in an animal model. J Vasc Res 46: 1-5.

13. Molacek J, Treska V, Kobr J, Houdek K, Holubec L, et al. (2011) Determination of adhesion molecules as a marker for inflammatory response in animal serum with experimentally created abdominal aortic aneurysm (AAA). Cardiovascular Continuum 2: 9-13.

14. Houdek K, Molacek J, Treska V, Krizkova V, Eberlova L, et al. (2013) Focal histopathological progression of porcine experimental abdominal aortic aneurysm is mitigated atorvastatin. Int Angiol 32: 291-306.

15. Liska V, Slowik P, Eggenhofer E, Treska V, Renner P, et al. (2009) Intraportal injection of porcine multipotent mesenchymal stromal cells augments liver regeneration after portal vein embolization. In Vivo 23: 229-35.

16. Liska V, Treska V, Mirka H, Kobr J, Sykora R, et al. (2009) Cytokines and liver regeneration after partial portal vein ligation in porcine experimental model. Bratisl Lek Listy 110: 447-53.

17. Liska V, Treska V, Mirka H, Kobr J, Sykora R, et al. (2012) Tumour necrosis factor-alpha stimulates liver regeneration in porcine model of partial portal vein ligation. Hepatogastroenterology 59: 496-500.

18. Liska V, Treska V, Mirka H, Kobr J, Sykora R, et al. (2012) Inhibition of transforming growth factor beta-1 augments liver regeneration after partial portal vein ligation in a porcine experimental model. Hepatogastroenterology 59: 235-40.

19. Sniderman KW, Sos TA (1978) Hepatic Schistosomiasis: A case with intrahepatic shunting and extrahepatic portal vein occlusion. Am J Roentgenol 130: 565-7. 20. Sheen CL, Lamparelli H, Milne A, Green I, Ramage JK (2000) Clinical features, diagnosis and outcome of acute portal vein thrombosis. QJM 93: 531-4.

21. Karunanithi MK, Michniewicy J, Copeland SE, Feneley MP (1992) Right ventricular preload recruitable stroke work, end-systolic pressure-volume And dP/ dTmax-end-diastolic volume relations compared as index of right ventricular contractile performance in conscious dogs. Circ Res 70: 1169-79.

22. Khan AN, Macdonald S, Sheen AJ, Tam CL, Sherlock D, et al. (2009) Portal vein thrombosis : 1-7.

23. Jacson P, Cockroft P (2007) Analgesia, anesthesia, and surgical procedures in the pig. Handbook of Pig Medicine. Saunders Elsevier.

24. Eidem BW, Tei C, O’Leary PW, Cetta F, Seward JB (1998) Nongeometric quantitative assessment of right and left ventricular function: myocardial performance index in normal children and patients with Ebstein anomaly. J Am Soc Echocardiogr 11: 849-56.

25. Pattoneri P, Pela G, Montanari E, Pesci I, Moruzzi P, et al. (2007) Evaluation of the myocardial performance index for early detection of mitoxantrone-induced cardiotoxicity in patients with multiple sclerosis. Eur J Echocardiogr 8: 144-50.

26. Bland JM, Altman DG (1986) Statistical methods for assessing agreement between two methods of clinical measurement. Lancet 1: 307-10.

27. Cheung MM, Smallhorn JF, Redington AN, Vogel M (2004) The effects of changes in loading conditions and modulation of inotropic state on the myocardial performance index: comparison with conductance catheter maesurements. Eur Heart J 25: 2238-42.

28. Hori Y, Uechi M, Indou A, Yamano S, Ebisawa T, et al. (2007) Changes in the myocardial performance index during dobutamine administration in anaesthetised cats. Am J Vet Res 68: 385-8.

29. Lavine SJ (2006) Effect of changes in contractility on the index of myocardial performance in the dysfunctional left ventricle. Cardiovasc Ultrasound 4: 45.

30. Tei C, Dujardin KS, Hodge DO, Kyle RA, Tajik AJ, et al. (1996) Doppler index combining systolic and diastolic myocardial performance: clinical value in cardiac amyloidosis. J Am Coll Cardiol 28: 658-64.

31. Koga S, Ikeda S, Urata J, Kohno S (2008) Effect of nasal continuous positive airway pressure in men on global left ventricular myocardial performance in patients with obstructive sleep apnea syndrome. Am J Cardiol 101: 1796-800.

32. Dujardin KS, Tei C, Yeo TC, Hodge DO, Rossi A, et al. (1998) Prognostic value of a Doppler index combining systolic and diastolic performance in idiopathicdilated cardiomyopathy. Am J Cardiol 82: 1071-6.

33. Peltier M, Slama M, Garbi S, Enriquez-Sarano ML, Goissen T, et al. (2002) Prognostic value of Doppler-derived myocardial performance index in patients with left ventricular systolic dysfunction. Am J Cardiol 90: 1261-3.

34. Senju N, Ikeda S, Koga S, Miyahara Y, Tsukasaki K, et al. (2007) The echocardiographic Tei-index reflects early myocardial damage induced by anthracyclines in patients with hematological malignancies. Heart Vessels 22: 393-7.

35. Tei C, Dujardin KS, Hodge DO, Bailey KR, McGoon MD, et al. (1996) Doppler echocardiographic index for assessment of global right ventricular function. J Am Soc Echocardiogr 9: 838-47.

36. Burgess MI, Mogulkoc N, Bright-Thomas RJ, Bishop P, Egan JJ, et al. (2002) Comparison of echocardiographic markers of right ventricular function in determining prognosis in chronic pulmonary disease. J Am Soc Echocardiogr 15: 633-9.

37. Eidem BW, O'Leary PW, Tei C, Seward JB (2000) Usefulness of the myocardial performance index for assessing right ventricular function in congenital heart disease. Am J Cardiol 86: 654-8.

38. Yacoub S, Birks EJ, Slavik Z, Henein M (2003) Early detection of myocardial dysfunction in Chagas disease using novel echocardiographic indices. Trans R Soc Trop Med Hyg 97: 528-34. 
39. Harada K, Tamura M, Toyono M, Yasuoka K (2002) Effect of dobutamine on a Doppler echocardiographic index of combined systolic and diastolic performance. Pediatr Cardiol 23: 613-7.

40. Patel N, Mills JF, Cheung MM (2009) Use of the myocardial performance index to assess right ventricular function in infants with pulmonary hypertension. Pediatr Cardiol 30: 133-7.

41. Tei C, Nischimura RA, Seward JB, Tajik AJ (1997) Non-invasive Doppler-derived myocardial performance index correlation with simultaneous measurements of cardiac catheterisation measurements. J Am Soc Echocardiogr 10: 169-78.

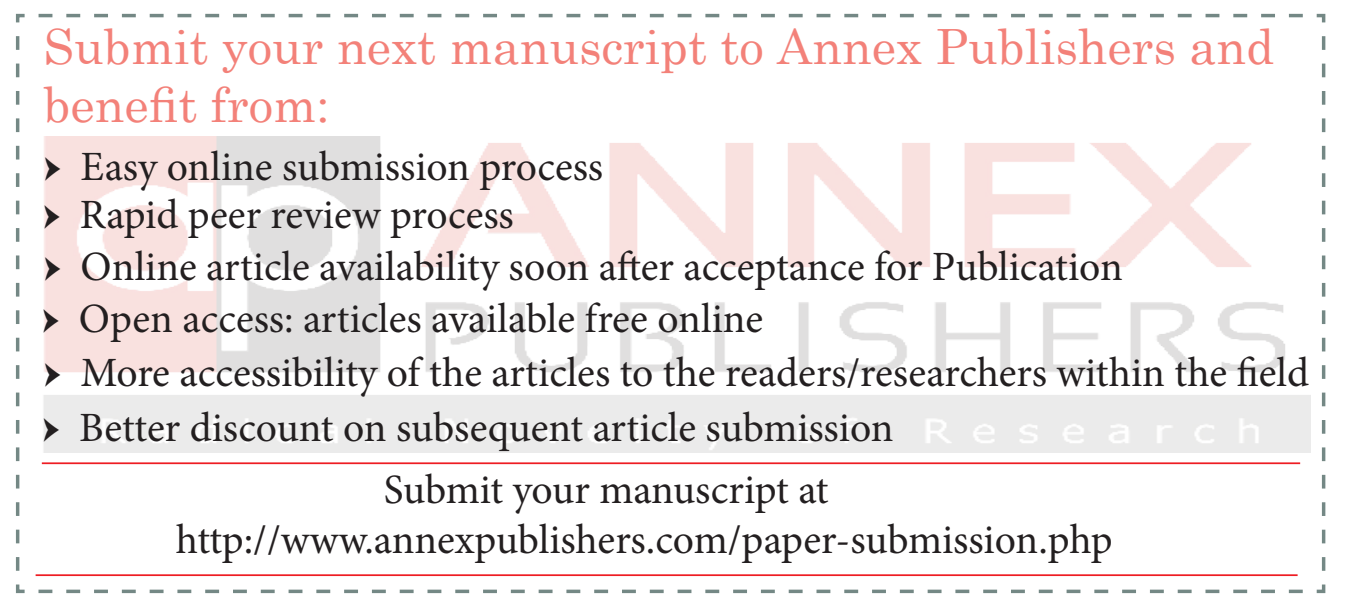

